\title{
Cultura Política e Teoria Política: dialogar para problematizar
}

\author{
Cultura Politica y Teoría Politica: dialogar para problematizar \\ Political Culture and Political Theory: dialogue to problematize
}

Valéria Cabrera Cabrera ${ }^{1}$

\begin{abstract}
Resumo
Pensar a Ciência Política hoje requer a clareza de que essa é uma subárea das Ciências Humanas dividida entre si. Durante a institucionalização acadêmica da Ciência Política como disciplina autônoma, estudos ditos "científicos" passaram a ser mais valorizados, o que acabou por segregar teoria e empiria. Ainda hoje, a cultura política e o institucionalismo compõem o mainstream da área, enquanto estudos de Teoria Política aparecem como menos dominantes, embora tenham tido êxito na busca por espaço na academia nos últimos anos. Nesse contexto, por meio da análise de aspectos essenciais à teoria da cultura política, este paper busca debater a ênfase dada por essa disciplina ao rebuscamento analítico-empírico decorrente do método estatístico de análise em detrimento do desenvolvimento teórico e crítico dos fenômenos em estudo. Nesse sentido, primeiramente, apresenta-se a teoria da cultura política e seus elementos essenciais, em seguida, questiona-se o conceito de democracia com que trabalha, o qual, segundo se percebe, conduz a um diagnóstico dos fenômenos políticos pouco problematizador e, por último, descreve-se porque se entende o diálogo com disciplinas próprias da Teoria Política necessário ao avanço da teoria da Cultura Política e à otimização de seus resultados empíricos.
\end{abstract}

Palavras-Chave: Cultura Política; democracia; democracia substancial; Teoria Política, diálogo.

\section{Resumen}

Pensar la Ciencia Política hoy requiere la claridad de que esa es una subárea de las Ciencias Humanas dividida entre sí. Durante la institucionalización académica de la Ciencia Política como disciplina autónoma, estudios denominados "científicos" pasaron a ser más valorados, lo que acabó por segregar teoría y empiria. En la actualidad, la cultura política y el institucionalismo componen el mainstream del área, mientras que los estudios de Teoría Política aparecen como menos dominantes, aunque han tenido éxito en la búsqueda de espacio en la academia en los últimos años. En este contexto, a través del análisis de aspectos esenciales a la teoría de la cultura política, este documento busca debatir el énfasis dado por esa disciplina al rebuscamiento analíticoempírico derivado del método estadístico de análisis en detrimento del desarrollo teórico y crítico de los fenómenos en estudio. En ese sentido, primero, se presenta la teoría de la cultura política y sus elementos esenciales, a continuación, se cuestiona el concepto de democracia con que trabaja, el cual, según se percibe, conduce a un diagnóstico de los fenómenos políticos poco problematizador y, por último, se describe porque se entiende el diálogo con disciplinas propias de la Teoría Política necesario para el avance de la teoría de la Cultura Política y la optimización de sus resultados empíricos.

Palabras claves: Cultura Política; democracia; democracia sustancial; Teoría Política, diálogo.

\begin{abstract}
Thinking about Political Science today requires the clarity that this is a subarea of the Human Sciences divided between them. During the academic institutionalization of Political Science as an autonomous discipline, socalled "scientific" studies became more valued, which eventually segregated theory and empiricism. Even today, political culture and institutionalism make up the mainstream of the area, while Political Theory studies appear to be less dominant, although they have succeeded in the quest for space in the academy in recent years. In this context, through the analysis of aspects essential to the theory of political culture, this paper seeks to discuss the emphasis given by this discipline to analytic-empirical research resulting from the statistical method of analysis,

\footnotetext{
${ }^{1}$ Mestra e doutoranda em Ciência Política; Programa de Pós-graduação em Ciência Política; Instituto de Filosofia, Sociologia e Política; Universidade Federal de Pelotas - UFPel; Pelotas, Rio Grande do Sul, Brasil; valeriacabreira@gmail.com
} 
to the detriment of the theoretical and critical development of the phenomena under study. In this sense, firstly, the theory of political culture and its essential elements is presented, then the concept of democracy with which it works is questioned, which, as it is perceived, leads to a diagnosis of political phenomena with little problematization, Finally, it is described why one understands the dialogue with disciplines proper to the Political Theory necessary to advance the theory of Political Culture and to optimize its empirical results.

Keywords: Political Culture; democracy; substantial democracy; Political Theory, dialogue.

\section{Introdução}

A Cultura Política é uma subárea da Ciência Política, cuja obra inaugural foi The Civic Culture, de Almond e Verba (1989 [1963])². Após as críticas dirigidas a essa obra, somente a partir da década de 1980 alguns autores se propuseram a estudar o comportamento político com a preocupação de evitar seus equívocos, sobretudo a partir da publicação de The Civic Culture Revisited, também de Amond e Verba (1980). No entanto, tem-se a percepção de que a teoria da cultura política está ainda baseada na negação de conceitos da obra inicial, de forma que os estudiosos de cultura política contemporâneos se centram preferencialmente nas pesquisas empíricas, feitas pelo método estatístico a partir de dados de opinião pública, com raras exceções.

Nesse sentido, este é um artigo que propõe um debate teórico sobre a subárea da cultura política, abordando o seu conceito contemporâneo de democracia como elementar à crítica aqui presente, sobretudo pensando-se esse conceito como um dos principais alvos de críticas já na época de Almond e Verba (1989 [1963]). Argumenta-se que no que se trata da democracia, a demarcação conceitual contemporânea parece não ser precisa. Nesse contexto, aborda-se a adoção da noção de democracia substancial pelos culturalistas contemporâneos numa tentativa de distanciarem-se do modelo minimalista de democracia. Por último, elaborase o argumento de que a atualização teórica da cultura política deve passar com um diálogo com a subárea da Teoria Política, numa disposição de ideias de cunho até ensaístico, mas que dão o passo inicial de reflexão sobre como e no que se crê necessário ainda avançar.

\section{Instruções gerais}

O liberalismo continua sendo a teoria mestra no que se refere à política, seja para os seus seguidores, seja para os seus críticos, os quais, segundo Miguel (2016, p. 25), “assumem os valores que o próprio liberalismo empunhou, para então criticar a sua concretização deturpada, enganosa ou insuficiente na ordem social que teria realizado o programa liberal”. Os valores a que se refere Miguel (2016) são a autonomia individual, referida há pouco, e a

\footnotetext{
${ }^{2}$ A versão dessa obra aqui utilizada foi publicada em 1989, apesar de a edição original ser de 1963.
} 
igualdade (MIGUEL, 2016). A democracia em sua versão liberal, nesse sentido, nega que a vontade popular seja o valor político último. Para os democratas liberais, o reconhecimento de um conjunto de liberdades básicas que permita aos seres humanos viverem como livres e iguais - tais como liberdades de pensamento, de expressão, de imprensa, de associação e de religião, de propriedade, de votar e ser votado - tem prioridade sobre as vontades e condições populares. Assim, a democracia liberal concede lugar mais amplo a princípios ligados à revisão judicial de questões sociais e políticas, como o check and balances, a separação de poderes e outros meios de mediar a vontade popular bastante comuns em democracias constitucionais ocidentais (GUTMAN, 2007).

Nesse sentido, a democracia aliada ao liberalismo acaba por limitar-se à proteção de direitos, o que, para Miguel (2016, p. 61) faz com que perca "a ambição de realizar a autonomia coletiva”. Em razão disso, as desigualdades socialmente estruturadas são subprestigiadas nessas democracias, onde quase não se percebe ligação entre a mudança social e a realização do ideal democrático (MIGUEL, 2016). Nesse contexto, a restrição da vontade popular à institucionalização de direitos e garantias individuais pode preservar ou promover as vantagens injustas das minorias que compões as elites (GUTMAN, 2007).

O liberalismo carrega contradições internas que colidem entre si e com a democracia. Ao mesmo tempo em que requer a igualdade de dignidade entre todas as pessoas e a positivação de direitos igualmente válidos para todos, compreende que a desigualdade é necessária e inevitável nas relações humanas, pois a racionalidade dos indivíduos seria desigual por natureza, o que justificaria a esfera pública estar aberta apenas para alguns. É nesse contexto que a ruptura proposta por Rawls com a caracterização de talentos individuais naturais é percursora de uma nova perspectiva (MIGUEL, 2016).

Feita uma breve introdução das questões críticas que envolvem a democraca liberal, o fato é que a cultura política tem sido apontada como uma teoria acrítica desse modelo de democracia (RENNÓ, 1998; PATEMAN, 1980). Entretanto, o argumento em defesa da cultura política é o de que os culturalistas teriam colocado em voga a opinião popular a partir do estudo das orientações subjetivas dos cidadãos acerca de fenômenos políticos justamente, segundo Rennó (1998, p. 71), "na tentativa de superar ideais liberais e iluministas".

Os conceitos-chave da área contemporanemente foram retirados de The Civic Culture Political Attitudes and Democracy in Five Nations, obra de Gabriel Almond e Sidney Verba, de 1963. No entanto, com efeito, ainda antes dessa obra, os estudos comportamentalistas surgiram nos Estados Unidos, berço da Ciência Política no século XIX, como um passo além daquilo existente na academia até aquele momento, isto é, representou a distinção entre, de 
um lado, a Ciência Política de fato científica e, de outro, a história do pensamento político e a teoria política normativa. Nesse período, que ficou conhecido como Behavioral Revolution, o positivismo lógico passou a servir como fundamento para a 'nova' Ciência Política, baseada na verificação empírica de teorias (FERES, 2000). Nesse período, David Easton anunciou a "morte da teoria política" (BALL, 2004, p. 10).

A teoria política acabou sendo absorvida pela filosofia, da qual os comportamentalistas estavam habituados a manterem-se distantes - o que para Ball (2004) parece bastante contraditório, já que o comportamentalismo era dependente de uma filosofia, o positivismo (BALL, 2004). Além disso, mesmo os partidários da revolução comportamentalista eram abertamente partidários do liberalismo democrático americano (FERES, 2000). Para Feres (2000), o problema dos estudos comportamentalistas da época era a confusão conceitual quanto à democracia. "Esses autores [os comportamentalistas] não raro tratam o liberalismo e o republicanismo americano como sinônimos", diz o autor (FERES, 2000, p. 102).

Ball (1993 apud Feres 2000) narra que mesmo antes da Behavior Revolution - que se deu a partir da década de 1950 - estudos comportamentalistas vinham ganhando espaço a partir da entrada dos Estados Unidos na II Guerra Mundial. Cientistas políticos se engajaram no estudo da guerra e o comportamentalismo passou a chamar a atenção dos governos e atuar a serviço da política de guerra. Após, quando iniciou-se a Guerra Fria, novamente o comportamentalismo mostrou-se útil para a "manipulação de corações e mentes" (FERES, 2000, p. 103). A utilidade desses estudos passou a exigir maiores finaciamentos, com o que a tecnificação dos estudos em Ciências Sociais contribuiu (FERES, 2000).

Essa narrativa ajuda a pensar nos motivos pelos quais o modelo de democracia liberal era enaltecido - ou, minimamente, não questionado - pelos estudos comportamentalistas do pós-guerra, passando pela Behavior Revolution e alcançando a abordagem culturalista a que ainda hoje se faz referência, a de Almond e Verba (1989). A crítica a The Civic Culture já foi largamente elaborada durante as décadas de 1970 e 1980, levando Almond a publicar The Civic Culture Revisited (1980), em que trouxe uma coletânea de textos críticos a premissas inaugurais. No entanto, em The Civic Culture Almond e Verba (1989) associaram as culturas políticas dos Estados Unidos e da Grã-Bretanha ao ideal de cultura cívica ou, na verdade, ao mais próximo disso (ALMOND; VERBA, 1989). Essas foram as palavras dos autores (1989, p. 338): 
política que, de acordo com as normas da ideologia democrática, seria encontrada em uma democracia bem sucedida (tradução nossa).

O aspecto que distanciava os demais países em estudo do ideal de cultura cívica, de acordo com a racionalidade-ativista esperada nas democracias de sucesso, era a escassez de maior envolvimento dos cidadãos com a política. Para Almond e Verba (1989, p. 338), "Segundo essa racionalidade-ativista, considerar uma democracia bem-sucedida exige que os cidadãos sejam envolvidos e ativos na política, informados sobre a política e influentes" (tradução nossa).

Até esse ponto, a noção de democracia de Almond e Verba (1989), ainda que claramente ligada às democracias liberais americana e britânica, poderia ainda estar adequada a algum leitor desavisado, sobremaneira ao considerar-se o desejo por participação cidadã. Um olhar um pouco mais aprofundado, contudo, revela a tomada a priori dos demais países como de cidadania pouco participativa, sem considerar os contextos sociais, políticos, econômicos, culturais e os processos históricos de formação desses países enquanto Estadosnacionais.

No que se refere à participação, Almond e Verba (1989, p. 340) afirmam que:

(...) o cidadão comum deve expressar seu ponto de vista para que as elites possam saber o que ele quer; ele deve estar envolvido; ele deve estar envolvido na política para que saiba e fiscalize se as elites estão ou não sendo sensíveis às suas demandas, e ele deve ser influente para impor o comportamento das elites (tradução nossa).

Vê-se que os autores sequer cogitam a possibilidade de atuação direta do cidadão nos governos; falam em influenciar, em se envolver, mas não em atuar ao lado das elites ou em lugar das elites. Sobre o tema, assim avalia Rennó (1998, p. 73) :

The Civic Culture adotou, além dessas tradições, o modelo liberal democrático de cidadania. O cidadão envolvido e ativo na vida política - com uma participação informada e racional, e, ao mesmo tempo, propenso à passividade, confiança e deferência à autoridade - é o protótipo desse padrão.

A relação entre cultura política e estrutura política foi talvez o maior ponto de divergênia em relação à The Civic Culture, que parecia não conseguir descrever de forma clara a relação entre os níveis micro e macro. Além disso, a teorização da área era considerada ineficiente como instrumento analítico da realidade política. E, obviamente, o claro favorecimento do modelo político democrático liberal pela abordagem culturalista não escapou das críticas (RENNÓ, 1998). Pateman (1980) ofereceu umas das mais reconhecidas contrubuições críticas a The Civic Culture. Para a autora essa obra não atentou para os motivos das descontinuidades vistas na cultura política das sociedades analisadas, de forma a 
deixar de tratar da relação entre diferenças internas de uma cultura política e igualdade formal institucionalizada. Isso, no entendimento de Pateman (1980), é consequência do fato de o modelo liberal de democracia não ser questionado por Almond e Verba (1989). Afora isso, a autora também enfatizou o fato de a teoria da cultura política ignorar o modelo participativo de democracia. Mais do que nunca a cultura política verificada a partir da participação afeta a estrutura política, de maneira que a adoção do modelo de demoracia liberal acaba por desconsiderar posicionamentos distintos dos indivíduos em relação à política (PATEMAN, 1980).

Rennó (1998) está de acordo com a noção de que a idealização da democracia angloamericana como modelo a ser perseguido restringe a capacidade de análise da relação entre cultura e estrutura político-social. No entanto, considera que a inserção dos conceitos de heterogeneidade cultural e de mudança cultural contribuíram para enriquecer a teoria da cultura política. No ensejo das críticas realizadas à abordagem culturalista, Rennó (1998) salienta a proposta de interpretação da cultura política elaborada por Lane, que considera Political Culture and Political Development, de Pye e Verba, um marco do distanciamento da cultura política contemporânea daquela de The Civic Culture, ao demonstrar uma visão da heterogeneidade cultural dos países (RENNÓ, 1998). Assim, coloca Rennó (1998, p. 86), se referindo à avaliação de Lane (1992):

[em Political Culture and Political Development] Há críticas quanto ao sistema de classificação de culturas políticas como paroquiais, subordinadas e participativas, é ressaltado o caráter transicional de todas as sociedades e, por último, defende-se a utilização de outras técnicas, além dos surveys, para a avaliação das culturas.

Para Lane (1992, apud Rennó, 1998) a observação das subculturas políticas associada à cultura política geral das sociedade evitaria a comparação das democracias das sociedades em estudos com modelos considerados universalmente desejáveis e, assim, a orientação ocidental e liberal. Nesse sentido, Rennó (1998, p. 89) conclui o seguinte:

O cuidado principal quando da utilização da teoria da cultura política é destacar alguns conceitos desse arcabouço teórico, capazes de enfrentar as dificuldades referentes à definição do tipo de relação entre cultura e estrutura política e à eliminação do viés democrático liberal, que ao invés de analisar culturas existentes, busca compará-las com um modelo ideal, sendo esse o da democracia liberal. A ênfase nas idéias de heterogeneidade cultural e de mudança na cultura política é indispensável para tornar a análise de determinado grupo mais precisa. 
Essa conclusão apresentada por Rennó (1998) é o que basicamente tem sido elaborado nos últimos anos pela cultura política contemporânea, o que tem sido útil para delinear os caminhos das pesquisas empíricas. A eliminação do viés democrático liberal, ao que tudo indica, é de difícil operacionalização, já que a grande maioria das sociedades contemporâneas são liberais. No entanto, a utilização desse modelo de democracia como um ideal tem sido rechaçado em prol de um modelo substancial.

\section{Democracia Substancial}

Pelo que se viu, a democracia liberal tem seu elemento democrático essencial na eleição de governos, enquanto em muitas democracias, como a do Brasil, a gramática é de exclusão, principal motivo pelo qual o modelo de democracia representativo, fruto do liberalismo, não poderia ser o referencial democrático por aqui. Como o liberalismo foi o grande vitorioso da Guerra Fria e a democracia em que se vive hoje é a liberal, hegemônica no ocidente, a conformação com esse modelo de democracia não apenas é escusável como é inevitável. O problema apontado central apontado na literatura está em não questionar esse modelo de democracia e em tomá-lo como referência, em uma atitude acrítica e não exigente para com o futuro. A principal saída dos culturalistas para escapar da atribuição de ausência de crítica ao modelo liberal de democracia, foi aliar-se à defesa de uma democracia substancial.

Assim, a noção de democracia substancial aparece para afirmar o distanciamento da noção de democracia da cultura política do modelo minimalista. Historicamente, muitos proponentes do regime democrático insistiram que os direitos formais de participar são necessários, mas não o suficiente para o governo genuíno pelo povo ser realizado. Rousseau e Mill argumentam que o autogoverno popular, nesse sentido, torna-se corrupto e, por fim, moribundo. Essa noção de que a participação democrática deve ser pensada como um dever cívico mais do que um direito, contudo, tem sido contestada por alguns teóricos modernos da democracia que alegam que um grau de apatia e desligamento político pode ser efetivo e funcionalmente necessário para o regime democrático estável (GUTMAN, 2007).

Numa evolução histórica conhecida dos estudos das elites, Schumpeter (1961) tornou-se a referência principal da noção de que o governo de elites era compatível com a democracia. Entretanto para esse autor a democracia tratava-se de um método político para escolha de governantes, e não de uma teoria com ideais. A partir do que Schumpeter denominou método democrático e do modelo de teoria clássica por ele delineado, outros autores, dentre eles Sartori, Eckstein, Dahl, Berelson, desenvolveram outras noções de 
democracia. Robert Dahl, por exemplo, ensaiou a o retorno do conceito de participação na formulação de seu método poliárquico, em que dispôs como pré-requisitos sociais do sistema poliárquico a existência de consenso a respeito das normas e a atividade política dos cidadãos (PATEMAN, 1992).

Em "Poliarquia - Participação e Oposição", originalmente publicada em 1972, Dahl (2005) evidenciou a possibilidade de que apenas uma pequena parcela de indivíduos aproveitasse as oportunidades de tomada de decisão e, assim, reconheceu que o controle do regime político ficaria por conta da competição entre os líderes, do mesmo modo já delineado por Schumpeter (1961). Em sentido oposto, contudo, Dahl (2005) ressaltou a importância da inclusão da maior quantidade possível de cidadãos na política, bem como da contestação aos governos por parte destes, para ampliar a influência de um maior número de minorias. Menciona Dahl (2005, p. 16):

\footnotetext{
Quanto menores os obstáculos à contestação pública e maior a proporção da população incluída no sistema político, mais dificuldade terá o governo de um país em adotar e aplicar políticas que exijam o exercício de sanções extremas contra uma porção maior do que uma pequena porcentagem da população; e menos provável, também, que o governo tente fazê-lo.
}

Poliarquia surgiu como uma forma de tentar compatibilizar o ideal democrático com o cenário político pouco participativo do pós-guerra. Dahl (2005) colocava em cena, assim, a questão da distribuição desigual dos recursos políticos e suas consequências para a democracia. No entanto, a inclusividade proposta pelo autor foi apenas formal, acabando por reduzir-se ao voto e à exclusão de grupos subalternos (MIGUEL, 2016).

Esses estudos influenciaram a maneira como o modelo de democracia representativo, atualmente vigente por aqui, foi construído. Nesse sentido, Pitkin $(1979 ; 2006)$ elaborou um dos mais conhecidos debates sobre o tema. Para essa autora, o representante, apesar de ter autonomia, não deve estar persistentemente em desacordo com os representados, os quais devem ter capacidade de atuar independentemente e de avaliar os fenômenos atinentes ao processo político. Interessante observar que Pitkin $(1979 ; 2006)$ constrói o seu entendimento a partir da crítica à teoria liberal de Burke, para quem o representante deveria atentar para o bem-estar geral da população, de forma a promover o interesse dos representados sem precisar consultar seus desejos. Isso, para a autora, se levado muito a sério, acabaria por formar um governo de experts e técnicos que decidem pela massa ignorante (PITKIN, 1979; 2006).

Nesse sentido, Baquero (2008, p.381) assim sintetiza: 


\begin{abstract}
Muito embora uma linha de pensamento na academia brasileira tenha se firmado nas últimas décadas argumentando que a democracia por aqui caminha bem, já que possui regras e procedimentos adequados para orientar os processos políticos, eleições regulares, pluripartidarismo e eleições transparentes, é equivocado entender aspectos procedimentais como suficientes a formação de uma teoria democrática capaz de explicar a complexidade política do país.
\end{abstract}

Para Baquero (2008, p. 382), “a democracia contemporânea requer uma cidadania ativa que se envolva na arena política via discussões, deliberações, referendos e plebiscitos, ou seja, por meio de mecanismos formais e informais". O autor ressalta, entretanto, que essa atuação não pode vir em prejuízo das instituições convencionais de mediação política. $\mathrm{Na}$ verdade, a necessidade do envolvimento popular para o fortalecimento democrático é consenso entre os teóricos contemporâneos. Ainda, Baquero (2008) sugere que verificar a percepção dos brasileiros sobre os principais problemas do país é uma boa forma de conhecer sobre a legitimidade democrática, sobretudo "tentando identificar se está em andamento uma institucionalização de valores pós-materiais” no país (BAQUERO, 2008, p. 387).

No que se refere ao fomento de valores pós-materiais tem-se certas objeções que ao final serão pontuadas. Entretanto, já se teve a oportunidade de discutir o tema em Linhares e Cabrera (2016), em que se chamou a atenção para a percepção negativa da população brasileira no que se refere à efetividade de direitos políticos, civis e sociais. Lá afirmou-se que o cidadão como agente político, sujeito de direitos políticos, civis e sociais, está subordinado à lei e tem o direito de ser tratado com respeito e justiça, tenha ou não cargo ou função pública. No entanto, acompanhou-se O’Donnel (2013) para lamentar que os vínculos que cercam as relações de poder nas sociedades, mesmo nas democráticas, fazem como que esses direitos constitucionais e legais na prática sejam negados a maioria da população (O’DONNEL, 2013; LINHARES; CABRERA, 2016).

A lógica de formação de crenças a respeito da política exige que se busquem outros fatores associados à participação política. Baquero (2008) vê a criação de capital social como um meio para a construção de uma cultura política participativa e, portanto, mais adequada à democracia substancial. Nesse sentido, o autor atribui a hibridez da democracia brasileira à precarização das condições de vida da população aliada à tendência contemporânea de manter-se um discurso que privilegia a democracia formal. Isso porque, o modelo de democracia representativo, típico da democracia liberal, além de não contar com a participação direta da população, tem tido suas instituições rechaçadas pela maioria dos cidadãos (BAQUERO, 2008). 
Em democracias consolidadas, mesmo que haja desconfiança institucional, não existem predisposições estruturais para mudar o regime democrático vigente. No caso das novas democracias a sobrevivência do regime ainda está em jogo e exige prudência, por isso a busca por elementos que gerem o apoio dos cidadãos aos princípios democráticos é importante. No mesmo sentido, a reforma estrutural que permita maior inserção popular nos processos decisórios é essencial. A exclusão dos cidadãos dos governos cria uma ausência de transparência que alavanca a percepção negativa sobre instituições representativas, as fragilizando (BAQUERO, 2008).

Assim, ilustra Baquero (2008, p. 391):

Por exemplo, as decisões que se tomam não são publicadas, persistem práticas clientelistas, a força das corporações e dos lobistas aumenta, podendo, assim, debilitar o regime democrático até torná-lo pouco representativo do interesse geral. Esta crise se materializa na medida em que o sistema político não consegue resolver, por meio de ajustes e pelas instituições convencionais da democracia representativa, suas contradições.

Neste contexto, perceba-se que as contradições existentes são produto do próprio modelo liberal democrático, que não elucida os dilemas centrais do país, ainda que políticas sociais sejam implementadas, gerando a crise. O alcance de um ideal de democracia substancial, isto é, que não privilegie apenas aspectos formais e institucionais, mas também a cultura política, a formação de capital social e a participação cidadã, assim, tem se chocado com a democracia represnetativa, sobretudo, em razão da desigualdade ser um desafio de superação nas sociedades liberais.

Com efeito, as construções teóricas atuais que adquirem maior espaço ao criticar liberalismo e marxismo são também liberais: deliberativismo liberal, comunitarismo liberal, multiculturalismo liberal, feminismo liberal, etc. Na verdade, as possibilidades de crítica da complexidade política e social atualmente têm sido elaboradas por meio do liberalismo. Assim, o fato de a cultura política ser uma teoria liberal ou que aceita a concepção liberal de democracia não é uma questão relevante. A questão de objeção está no fato de as saídas encontradas pelos estudos contemporâneos fornecerem poucos elementos de crítica a esse ideal democrático, isto é, a noção de democracia substancial somente poderá constituir-se como alternativa real à concepção liberal de democracia se incorporar outros elementos que não a mera negação à definição minimalista.

\section{Objeções e diálogo com a Teoria Política}


Exemplo do que se vinha falando acima é a adoção do pós-materialismo como uma das aspirações da democracia substancial (aí está a objeção referida acima). A lógica da teoria pós-materialista interpreta a mudança sociopolítica contemporânea como um processo de desenvolvimento humano, que faz com que os cidadãos deem cada vez mais valor à liberdade humana e à autoexpressão. Os argumentos principais da teoria associam o desenvolvimento socioeconômico ao estabelecimento de valores pós-materialistas, os quais favoreceriam a instauração de regimes democráticos (INGLEHART; WELZEL, 2009). Isso significa que mais uma vez a democratização é atrelada ao avanço material das sociedades.

Assim, são importadas definições teóricas que originalmente pensam sobre países avançados economicamente e, em consequência, esse aporte torna-se precário para pensar realidades regionais. Na América Latina, por exemplo, o impasse com grupos culturais e étnicos inicia-se lá na colonização onde a população indígena foi transplantada para um contexto que não era seu, escravizada e dizimada. No que se refere a estudos culturais, mesmo o multiculturalismo, que, em tese, estaria muito a frente ao pensar além de fatores econômicos, não é capaz de problematizar as condições que fizeram com que determinados grupos se tornassem minoritários. A permanência do laço com a ideia de identidade de pertencimento social nacional tem causado importantes equívocos de interpretação, ainda mais quando utilizada como metodologia de pesquisa, comprometendo a forma de fazer política e teoria política ${ }^{3}$.

No Brasil, discussões como aquela sobre o fechamento de comunidades indígenas faz ver que discursos conservadores ganham lugar em um momento em que o liberalismo já não consegue suportar tantas demandas. $\mathrm{O}$ argumento do pluralismo razoável da sociedade liberal e da neutralidade do Estado não alcançam questões como tais, de cunho histórico e cultural. Nesses casos, parece preferível o entendimento de que as demandas em sociedades de industrialização e democracia não avançadas devem ser analisadas individualmente, por meio do estudo do caso em concreto, pois adotar premissas de uma ou de outra teoria explicativa leva a uma generalização que explica sem problematizar. No caso do pósmaterialismo, além de já se saber que não há muitos pós-materialistas no Brasil (RIBEIRO, 2011), não se vê qualquer indício de que a democracia por aqui alcançaria a plenitude se o país obtivesse avanço material. As desigualdades não materiais são essenciais para compreender-se a complexidade social e política por aqui.

\footnotetext{
${ }^{3}$ Importante fazer referência que a construção desse argumento surgiu em debate com a professora Luciana Ballestrin durante disciplina por ela ministrada junto ao Programa de Pós-graduação do qual faz parte a autora deste artigo.
} 
Aliado a isso, em um período em que as novas modalidades de participação direta e deliberação precisam ser debatidas, sobretudo a partir da sua relação com os tradicionais mecanismos de representação, perceber como a teoria da cultura política - uma das subáreas mainstreams da ciência política - se insere ou não nesse debate parece essencial. Ainda mais no contexto de crise social, política e econômica presente em diversos países latinoamericanos, e percebido sobremaneira pelos brasileiros.

O discurso participativista está na maioria dos textos da área da cultura política. Em The Civic Culture, Almond e Verba (1989) já afirmavam que o futuro da democracia seria de participação, embora basicamente se referissem a escolha de representantes. É corrente na literatura a noção de que democracias estabelecidas e emergentes possuem desafios diversos no que se refere à participação política. Enquanto as democracias estabelecidas precisariam expandir as oportunidades de participação direta dos cidadãos na política - a fim de que estes tenham papel significativo na tomada de decisões cujos resultados afetam suas vidas - as democracias emergentes que, em muitos casos tiveram a democratização possibilitada, entre outros fatores, pela movimentação popular, necessitariam incutir nos cidadãos o hábito da participação convencional (DALTON; KINGLEMANN, 2007).

Há muitos estudos da mais alta relevância sobre participação política no Brasil elaborados por pesquisadores de cultura política (BORBA, RIBEIRO, 2010, 2011; DELLA PORTA, 2010). A ressalva que se faz não é em relação às pesquisas empíricas, que trazem conclusões importantes para o entendimento da política nacional, mas ao uso do conceito de democracia participativa no âmbito da cultura política. Como a teoria de base original da cultura política não é em si participativista, a apropriação do conceito de democracia participativa acaba por ignorar a maioria das formas de participação direta e, inevitavelmente, implica a redução do alcance desse modelo. Adota-se a premissa de que o fomento à participação política é essencial à democracia, mas não se assume motivações, explicações e fatores levantados na larga teorização já desenvolvida pelos participativistas no âmbito da teoria política normativa, bem como não se elaboram conceitos novos a desenvolver a teoria da cultura política.

A teoria participativa contemporânea, em sua forma revista, exige não apenas a coexistência de formas de representação e de participação popular, mas também o reconhecimento de um procedimentalismo participativo, onde processos de deliberação pública podem substituir parte do processo de representação. Nesse contexto, os meios de participação direta existentes no Brasil atualmente são basicamente as conferências e conselhos, que promovem a representação da sociedade civil na esfera dos governos, seja 
deliberativa ou consultivamente. Os estudos contemporâneos de cultura política, no entanto, atrelados em maioria ao método survey de coleta de dados e estatístico de análise e, portanto, em grande parte sujeitos a bancos de dados secundários, muito pouco frequentemente estuda essas formas de participação. O mesmo se dá em relação aos movimentos sociais, sobre os quais porcentagens baixíssimas de respondentes de pesquisas survey afirmam participar. Talvez pela pouca representação estatística esses movimentos quase não são objeto de estudos culturalistas, quando são os principais potencializadores da participação política não convencional no Brasil. É compreensível que seja custoso despender tempo e dinheiro com porcentagem tão pequena de cidadãos; contudo, é preciso admitir que os estudos da área não têm a capacidade de explicar o fenômeno da participação por completo.

Compatibilizar o pluralismo com a concentração de renda existente em países do Sul Global, além disso, é a grande questão. Dizer que a participação é aberta a todos é algo muito distante de afirmar que a participação é alcançada por todos, pois as posições sociais são por demais desiguais entre indivíduos nas sociedades contemporâneas. Isso não é incorporado à noção de cultura política de Almond e Verba (1989) e até hoje a limitação da abordagem para fazer frente a essa questão é aparente. Isso porque, ainda que a cultura política contemporânea pense na participação política, apenas a minoria das análises adentram em formas de participação direta em meios governamentais ou abordam movimentos sociais e a atuação da sociedade civil, ficando o associativismo restrito ao estudo do capital social.

Ainda, autores contemporâneos fazem parte de um grupo que estuda comportamento político evitando os equívocos das concepções inaugurais da área. A orientação é que se trabalhe com subculturas, utilizando-se dados sociodemográficos, e que se interpretem os resultados pelo contexto histórico social do local e do período em análise. A questão é até que ponto amealhar um conjunto de variáveis sociodemográficas faz de fato analisar a complexidade social, quando essas variáveis são utilizadas na explicação de fenômenos relacionados à aspectos formais da democracia. Depois, é importante pensar em que medida a demarcação de resultados por variáveis sociodemográficos demonstram a complexidade social de fato. Nas pesquisas survey, a questão de gênero, por exemplo, fica limitada a escolha binária entre homem e mulher, logo identidades não são consideradas, interseccionalidades também não são, a divisão da esfera pública e privada posta pela perspectiva liberal, que por muitas vezes possibilita o tratamento das questões de gênero como privadas, sequer são pensadas.

Além disso, a cultura política elabora análises por meio de método de coleta de dados de opinião pública na busca de determinantes individuais de atitudes e comportamentos em 
relação à fenômenos e processos políticos. Não se pretende cair naquele argumento de que a cultura política trabalha com um amontoado de opiniões e as chama de cultura. É sabido que o encontro de padrões ou não de atitudes e comportamentos permitem que se distingua crenças, valores, normas e opiniões, ainda que, sobretudo, para analistas do discurso, o método seja pouco ontológico. O ponto está no fato de que as pesquisas inevitavelmente são sobre a democracia institucional: confiança nas instituições e satisfação com governos como elementos que suportam a legitmidade democrática, nos moldes postos por Moisés (1995). Nesse sentido, quando a cultura política se apresenta como alternativa ao neoinstitucionalismo, falha em fazê-lo. Diz que a cultura política importa para o estudo da estabilidade democrática, mas permanece no estudo das instituições, ou seja, continua a ter a democracia institucional como referência de democracia. Isso ocorre, segundo se entende, porque os estudos contemporâneos apenas buscam inserir em seus estudos elementos relevantes provenientes de outras vertentes teóricas, preocupando-se mais fequentemente com a análise empírica e menos com teorização, reanálise de conceitos e, principalmente, diálogo transformador com a teoria política.

Assim, salienta-se que não obstante a crítica de que a cultura política não tem um conceito de democracia e, por isso, adequa-se à democracia posta, tenha sido elaborada à The Civic Culture, ainda hoje esse é um conceito que permanece precário. Depois, afirma-se que o diálogo entre subáreas da ciência política é urgente, principalmente das áreas ditas "mais científicas" com a teoria política - que está muito a frente no que se refere ao desenvolvimento teórico adequado à complexidade social e política. No entanto, isso não significa aproveitar partes convenientes descontextualizadas das premissas culturalistas ou utilizar referências teóricas apenas para demonstrar conhecê-las, ignorando seus objetos, métodos e suas interpretações ao realizar pesquisas empíricas. Isso porque, as premissas da teoria política normativa contemorânea seriam contraditórias a qualquer conceito muito distante do da democracia posta, institucionalizada, liberal.

Análises desse tipo enriqueceram a abordagem culturalista ao considerar a heterogeneidade de culturas, o que representou grande avanço pós-críticas. No entanto, a permanente ausência de um conceito de democracia, numa tácita aceitação do modelo liberal, tornou contraditória a relação entre o esforço pela incorporação de subculturas e a continuidade de um ideal de democracia pouco favorável à inclusão social. Nesse sentido, são produzidas conclusões escorregadias, que, segundo se percebe, escapam das intenções dos autores da áreas, claramente opostas. 
O rechaço a priori das críticas passadas como se agora existisse uma nova cultura política, não convence. Não se entende razoável que uma teoria se funde em negações de conceitos. É preciso reteorizar e criar algo realmente novo, isto é, fazer do diálogo com a teoria política um meio de transformação dos seus conceitos, para que posteriormente embasem novas interpretções das pesquisas, de forma a dar conta empiricamete de toda a complexidade já desvendada pela teoria política normativa. Isso porque, enquanto isso não for elaborado, a aceitação tácita à democracia liberal permancerá. A propósito, reafirma-se, a adversidade está em tomar a democracia liberal como ponto de chegada, quando serve apenas para ponto de partida. É preciso adotar uma perspectiva crítica a partir de um incansável e permanente ponto de referência futuro, sendo exigente com o que se deseja para democracia.

\section{Conclusões}

A discussão posta aqui faz chamar atenção para o fato de que a demarcação contemporânea do conceito de democracia por parte da cultura política não é clara, na medida em que o esforço para inserir a noção de democracia substancial não supera a negação da noção minimalista de democracia. Que a cultura política e a participação importam é fato inegável; resta demarcar que democracia se espera consolidar, o que pode ser iniciado pelo aprofundamento do entendimento de heterogeneidade cultural e pela reelaboração de formas de mudança cultural para além dos valores pós-materiais.

Assim, aponta-se como necessário o diálogo entre as subáreas da ciência política, pois muitas vezes são analisados os mesmos fenômenos a partir de metodologias distintas, desconsiderando-se o quão produtivo seria a discussão conjunta de resultados (e não sugiro que o esforço deva vir apenas dos estudiosos de cultura política). No caso da cultura política, o ideal democrático utilizado como referência das análises deve ser mais do que o funcionamento institucional e positivação de liberdades. Se dispor a estudar a democracia exige, portanto, mais do que a observação de dados de opinião pública por região, idade, etnia, gênero, pois todas essas categorias são também problematizáveis no emaranhado de desigualdades sociais estruturais dos países de democracia não avançadas. É importante fomentar o discernimento crítico ao aliar-se ou não de maneira inequívoca a concepções teóricas bem-intencionadas, mas que explicam pouco para além da democracia liberal.

\section{Referências}

ALMOND, G. A.; Verba, S. The Civic Culture - Political Attitudes and Democracy in Five Nations. Stanford, EUA: Sage Publications, 1989. 585 p. 
ALMOND, G. A. The Intelectual History of the Civic Culture. In: The Civic Culture Revisited. Gabriel Almond Sidney Verba (org). Boston, Little, Brown and Company, 1980. 1$36 \mathrm{p}$.

BALL, T. Aonde vai a teoria política? Revista de Sociologia e Política. n 23, p. 9-22, nov, 2004. ISSN 1678-9873. Disponível em: <http://www.scielo.br/pdf/rsocp/n23/24618.pdf.> Acesso em: 20 de maio de 2017.

BAQUERO, M. Construindo uma outra sociedade: o capital social na estruturação de uma cultura política participativa no Brasil. Revista de Sociologia e Política n. 21, p. 83-108, nov, 2003. ISSN 1678-9873. Disponível em: <http://www.scielo.br/scielo.php?pid=S0104$44782003000200007 \&$ script=sci_abstract\&tlng=pt>. Acesso em: 03 de junho de 2016.

BAQUERO, M. Democracia formal, cultura política informal e capital social no Brasil. Opinião Pública. v. 14, n 2, p. 380-413, nov, 2008. ISSN 1807-0191. Disponível em: <http://www.scielo.br/pdf/op/v14n2/05.pdf>. Acesso em: 15 de julho de 2017.

BORBA, J.; RIBEIRO, E. Participação convencional e não convencional na América Latina. In: Cultura(s) Política(s) e Democracia no Século XXII na América Latina. Marcello Baquero (Org). Porto Alegre: UFRGS, 2011, p. 95-118.

BORBA, J; RIBEIRO, E. As dimensões da participação política no Brasil. Toeria e Pesquisa: Revista e Ciência Política. V. 20, n. 2, 2011. ISSN 2236-0107. Disponível em: <http://www.teoriaepesquisa.ufscar.br/index.php/tp/article/view/261/191>. Acesso em: $20 \mathrm{de}$ setembro de 2017.

DALTON, R; KLINGEMANN, H. Oxford Handbook of Political Behavior. Oxford: Oxford University Press, 2007, 1008 p.

DAHL, R. A. Poliarquia e Oposição. $1^{\text {a }}$ reimpressão. São Paulo: Editora USP, 2005, 481 p.

FERES, J. J. Aprendendo com os erros dos outros: o que a história da ciência política americana tem para nos contar. Revista de Sociologia e Política, n. 15, p. 97-110, nov, 2000, ISSN 1678-9873. Disponível em: <http://www.scielo.br/scielo.php?pid=S0104$44782000000200007 \&$ script=sci_abstract\&tlng=pt $>$. Acesso em: 2 de junho e 2017.

GUTMAN, A. Democracy. In: A Companion to Contemporary Political Philosophy. Robert E. Goodin, Philip Pettit e Thomas Pogge (Org.), v. 1. 2 ed. Blackwell Publishing, 2007, p. 521-531.

INGLEHART, R; WELZEL, C. Modernização, mudança cultural e democracia: a sequência do desenvolvimento humano. Tradução de Hilda Nara Lemos Pantoja Coelho; revisão técnica Benício Vieiro Schimidt. São Paulo: Francis, 2009, 399 p.

LINHARES, B. F.; CABRERA, V. C. Cultura política y la percepción de Protección de los Derechos Humanos en Brasil: una cara de la calidad de la democracia en el país. Revista Política, Globalidad y Ciudadanía, v. 2, n. 3, jun de 2016, ISSN 2395-8448, p. 68-85. 
Disponível em: <http://revpoliticas.uanl.mx/RPGyC/index.php/RPGyC/article/view/42>. Acesso em: 02 de junho de 2017.

MIGUEL, L. F. O liberalismo e o desafio das desigualdades. In: Desigualdades e Democracia: o debate da teoria política. Luís Felipe Miguel (Org.). São Paulo: Editora Unesp, 2016. 36-75 p.

MOISÉS, J. A. Os brasileiros e a democracia: bases socio-políticas da legitimidade democrática. Ática: São Paulo, 1995, 301 p.

MOISÉS, J. A. Cultura política, instituições e democracia. Revista brasileira de ciências sociais. v. 23, n. ${ }^{\circ}$ 66, p. 11-43, fev, 2008, ISSN 1806-9053. Disponível em: <http://www.scielo.br/pdf/rbcsoc/v23n66/02.pdf >. Acesso em15 de janeiro de 2017.

O'DONNEL, G. Democracia, desenvolvimento humano e direitos humanos. Revista Debates. v. 7, n. 1, p. 15-114, abril, 2013, ISSN 1982-5269. Disponível em: <https://seer.ufrgs.br/debates/article/view/36892/24040>. Acesso em: 12 de junho de 2017.

PATEMAN, C. The Civic Culture: A Philosophic Critique. In: The Civic Culture Revisited. Gabriel Almond e Sidney Verba (Org.). Little Brown, and Company, 1980. p. 65-90.

PATEMAN, C. Teorias recentes da democracia e o 'mito clássico'. In: Participação e Teoria Democrática. São Paulo: Paz e Terra, 1992. p. 9-34.

PITKIN, H. F. O conceito de Representação. In: Política e Sociedade. Fernando Henrique Cardoso e Carlos Estevam Martins (Org). v. 2, São Paulo: Companhia Editora Nacional, 1979.

PITKIN, H. F. Representação: palavras, instituições e ideias. Lua Nova, São Paulo, v. 67, p. 15-47, 2006, ISSN 1807-0175. Disponível em: <http://www.ipea.gov.br/participacao/images/pdfs/participacao/outras_pesquisas/pitkin.pdf>. Acesso em: 04 de junho de 2017.

RENNÓ, L. Cultura política: vícios e virtudes. Revista Brasileira de Informação Bibliográfica em Ciências Sociais, Rio de Janeiro, n. 45, p. 71-92, 1998, ISSN 2317-6644. Disponível em: <file:///C:/Users/cabre/AppData/Local/Packages/Microsoft.MicrosoftEdge_8wekyb3d8bbwe/ TempState/Downloads/bib45_4\%20(1).pdf>. Acesso em: 15 de julho de 2017.

RIBEIRO, E. A. Valores pós-materialistas e cultura política no Brasil. Maringá: Eduem, 2011, p. 214.

SCHUMPETER, J. A. Capitalismo, Socialismo e Democracia. Rio de Janeiro: Editora Fundo de Cultura, 1961, 582 p. 